University of Nebraska - Lincoln

DigitalCommons@University of Nebraska - Lincoln

Faculty Publications from the Harold W. Manter Laboratory of Parasitology

$12-1998$

\title{
A New Eimeria Species (Apicomplexa: Eimeriidae) Infecting Onychomys Species (Rodentia: Muridae) in New Mexico and Arizona
}

John A. Hnida

Peru State College

Wade D. Wilson

University of New Mexico, wwilson@unm.edu

Donald W. Duszynski

University of New Mexico, eimeria@unm.edu

Follow this and additional works at: https://digitalcommons.unl.edu/parasitologyfacpubs

Part of the Parasitology Commons

Hnida, John A.; Wilson, Wade D.; and Duszynski, Donald W., "A New Eimeria Species (Apicomplexa: Eimeriidae) Infecting Onychomys Species (Rodentia: Muridae) in New Mexico and Arizona" (1998). Faculty Publications from the Harold W. Manter Laboratory of Parasitology. 182.

https://digitalcommons.unl.edu/parasitologyfacpubs/182

This Article is brought to you for free and open access by the Parasitology, Harold W. Manter Laboratory of at DigitalCommons@University of Nebraska - Lincoln. It has been accepted for inclusion in Faculty Publications from the Harold W. Manter Laboratory of Parasitology by an authorized administrator of DigitalCommons@University of Nebraska - Lincoln. 


\title{
A NEW EIMERIA SPECIES (APICOMPLEXA: EIMERIIDAE) INFECTING ONYCHOMYS SPECIES (RODENTIA: MURIDAE) IN NEW MEXICO AND ARIZONA
}

\author{
John A. Hnida, Wade D. Wilson, and Donald W. Duszynski \\ Department of Biology, University of New Mexico, Albuquerque, New Mexico 87131
}

\begin{abstract}
Fecal samples from 3 species of Onychomys (Rodentia: Muridae) captured in New Mexico and Arizona were examined for coccidia. Six of the $59(10 \%)$ were infected with a new species of Eimeria. Sporulated oocysts $(\mathrm{n}=105)$ of this new species are subspheroidal, $17.4 \times 16.1(14-21 \times 13-19) \mu \mathrm{m}$, with ellipsoidal sporocysts $10.4 \times 5.7(9-12 \times 5-8) \mu \mathrm{m}$. This species occurred in 3 of 24 (13\%) Onychomys arenicola, 2 of 31 (6\%) Onychomys leucogaster from New Mexico, and 1 of $4(25 \%)$ Onychomys torridus from Arizona. Isolates recovered from $O$. leucogaster and $O$. torridus were inoculated into $O$. leucogaster $(n=5)$ and produced infections with a prepatent period of 7 days and a patent period of 7-23 days.
\end{abstract}

There are 3 species of Onychomys, or grasshopper mice, but to date only 1 coccidian has been described from these predatory rodents, i.e., Eimeria onychomysis Levine, Ivens, and Kruidenier, 1957. Recent parasitological work on grasshopper mice has included studies on helminths (Pfaffenberger et al., 1985) and ectoparasites (Pfaffenberger and DeBruin, 1986; Thomas, 1988), but the only recent survey for coccidia of Onychomys included just 2 individuals, and neither was shedding oocysts (McAllister et al., 1991). Herein, we describe a new species of Eimeria that was recovered from the feces of all 3 species of Onychomys that were trapped in the southwestern United States.

\section{MATERIALS AND METHODS}

Feces were taken from the intestines of Onychomys leucogaster and Onychomys arenicola that were collected as part of The University of New Mexico's Long Term Ecological Research (LTER) project on the Sevilleta National Wildlife Refuge, Socorro County, New Mexico during 1993-1996 (see Wilson et al., 1997). All voucher specimens of hosts from the LTER were deposited in the Museum of Southwestern Biology, the University of New Mexico (MSB). In addition, in December 1996, feces were collected from live Onychomys torridus that were trapped on permanent plots located at the Cave Creek Bajada, San Simon Valley, near Portal, Arizona (see Brown and Munger, 1985). Procedures for experimental inoculations of captive-reared $O$. leucogaster followed Upton et al. (1992); inoculation doses ranged from $\sim 10$ to 1,000 oocysts. All procedures for preserving fecal material as well as measuring and photographing oocysts were described earlier (Duszynski et al., 1982; Stout and Duszynski, 1983). The species description is based on guidelines by Duszynski and Wilber (1997); measurements are in $\mu \mathrm{m}$, with size ranges in parentheses following the means.

\section{DESCRIPTION}

Eimeria sevilletensis n. sp.

$$
\text { (Figs. 1-4) }
$$

Description: Oocyst subspheroidal, occasionally spheroidal, with wall 1.3 thick $(0.9-2.2)(n=103)$, composed of 2 layers; outer layer smooth, colorless to light yellow-brown, $\sim 1 / 2$ of total thickness, inner layer smooth, colorless to light yellow-green; micropyle and oocyst residuum absent, but $1-2$ (occasionally 0 ) relatively large polar granules present, $1.8 \times 1.3(1.0-2.5 \times 0.5-2.5)(\mathrm{n}=75)$; sporulated oocysts $(\mathrm{n}$ $=105), 17.4 \times 16.1(14-21 \times 13-19)$, with $\mathrm{L}: \mathrm{W}$ ratio $1.1(1.0-1.2)$; sporocysts ellipsoidal, $10.4 \times 5.7(9-12 \times 5-8)$, with $\mathrm{L}: \mathrm{W}$ ratio 1.8 (1.5-2.2); Stieda body present, small and button-like, but sub- and parastieda bodies absent; sporocyst residuum typically a large, compact mass of many fine granules located between and sometimes obscuring the sporozoites; sporozoites elongate, with 1 end rounded and the other tapering, lacking refractile globules.

Received 16 December 1997; revised 29 June 1998; accepted 5 July 1998.

\section{Taxonomic summary}

Symbiotype: Onychomys arenicola Mearns, 1896, Mearn's grasshopper mouse.

Other hosts: Onychomys leucogaster (Wied-Neuwied, 1841), northern grasshopper mouse; O. torridus (Coues, 1874), southern grasshopper mouse (scorpion mouse).

Type locality: U.S.A., New Mexico, Socorro Co., Sevilleta National Wildlife Refuge, Grassland-east trapping site, Web $1\left(106^{\circ} 43^{\prime} 31^{\prime \prime} \mathrm{W}, 34^{\circ}\right.$ $\left.20^{\prime} 7^{\prime \prime} \mathrm{N}\right)$.

Other localities: U.S.A., New Mexico, Socorro Co., Sevilleta National Wildlife Refuge, Creosote-east trapping site, Web $2\left(106^{\circ}\right.$ $\left.43^{\prime} 57^{\prime \prime} \mathrm{W}, 34^{\circ} 19^{\prime} 52^{\prime \prime} \mathrm{N}\right)$, Web $4\left(106^{\circ} 44^{\prime} 22^{\prime \prime} \mathrm{W}, 34^{\circ} 20^{\prime} 3^{\prime \prime} \mathrm{N}\right)$; Creosotewest trapping site, Web $1\left(106^{\circ} 55^{\prime} 26^{\prime \prime} \mathrm{W}, 34^{\circ} 17^{\prime} 42^{\prime \prime} \mathrm{N}\right)$; Grassland-east trapping site, Web $4\left(106^{\circ} 43^{\prime} 13^{\prime \prime} \mathrm{W}, 34^{\circ} 20^{\prime} 10^{\prime \prime} \mathrm{N}\right)$; Arizona, Cochise Co., San Simon Valley, Cave Creek Bajada, $6.5 \mathrm{~km} \mathrm{E,} 2 \mathrm{~km} \mathrm{~N}$ of Portal.

Prevalence: Onychomys arenicola: 3 of $24(13 \%)$ in New Mexico, 1995-1996; O. leucogaster: 2 of 31 (6\%) in New Mexico, 1995-1996; O. torridus: 1 of $4(25 \%)$ in Arizona, 1996.

Site of infection: Unknown, oocysts recovered from intestinal contents.

Prepatent period: Seven days after inoculation (DAI) in $O$. leucogaster (experimental; $\mathrm{n}=5$ ).

Patent period: Seven to 23 DAI in $O$. leucogaster (experimental; $n$ $=5)$.

Pathogenicity: The feces of 3 animals, each receiving $\sim 1,000$ sporulated oocysts, became loose but formed and darker in color within 69 DAI and remained so throughout the patent period.

Cross-immunity: Two animals, each inoculated with the proposed species within 5-7 days after the last day of patency resulting from experimental infections with Eimeria onychomysis, developed infections whose prepatencies, patencies, and intensities were indistinguishable from those of experimentally infected animals with no prior exposure to E. onychomysis.

Sporulation time: Two to 3 days at $\sim 25 \mathrm{C}$.

Material deposited: Phototype (see Bandoni and Duszynski, 1988) of sporulated oocysts in the United States National Parasite Collection (USNPC), no. 88173. Symbiotype (see Frey et al., 1992): O. arenicola in the MSB no. 85073 (NK 40134, male, 21 May 1996).

Etymology: The nomen triviale is derived from the collection locality where we first encountered this coccidian.

\section{Remarks}

Eimeria sevilletensis is the second Eimeria species to be described from the genus Onychomys; the first was E. onychomysis Levine, Ivens, and Kruidenier, 1957, collected from $O$. leucogaster from Arizona (Levine et al., 1957). The new species differs from E. onychomysis in the mean size of its oocyst $(17.4 \times 16.1$ vs. $20 \times 19)$ and sporocyst $(10.4$ $\times 5.7$ vs. $11 \times 8$ ), in lacking an oocyst residuum, and in having a button-like and less prominent Stieda body. Among Eimeria from other hosts in the subfamily Sigmodontinae, E. sevilletensis is most similar to Eimeria knoxjonesi Duszynski and McAllister, 1995, from Peromyscus pectoralis from Texas (Duszynski and McAllister, 1995). Like E. knoxjonesi, the new species has a smooth, bilayered wall, a small button-like Stieda body, lacks an oocyst residuum, and is similar in the 

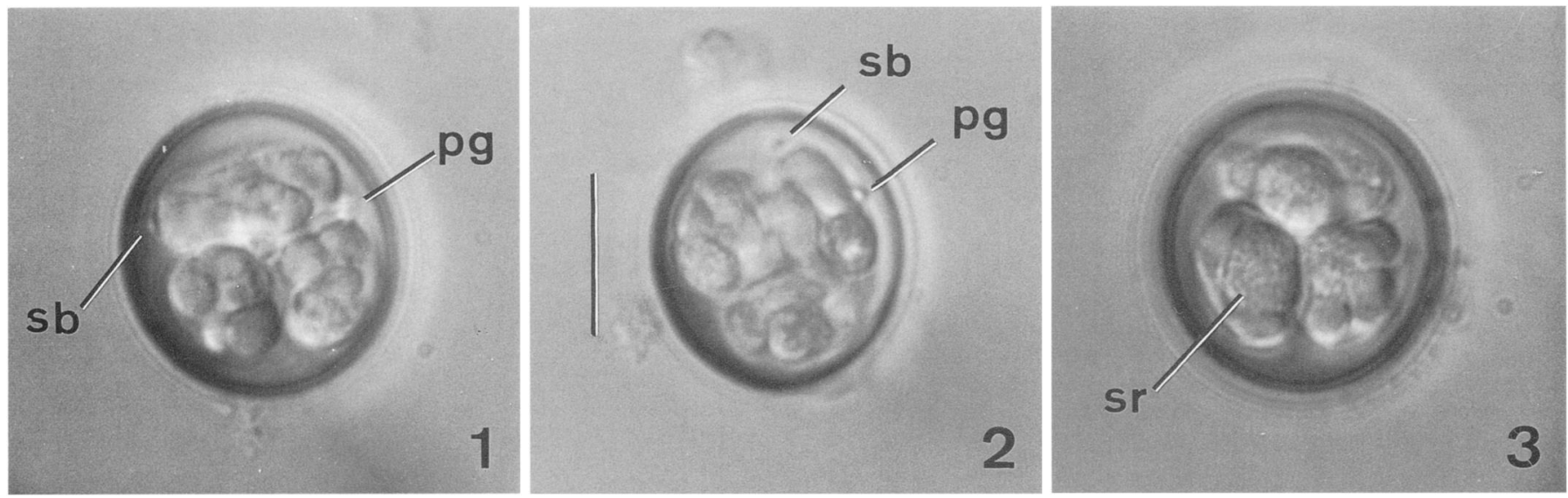

FIGURES 1-3. Photomicrographs of sporulated oocysts of Eimeria sevilletensis n. sp. recovered from the feces of Onychomys arenicola captured at the Sevilleta National Wildlife Refuge, Socorro County, New Mexico, U.S.A. Scale bar $=10 \mu \mathrm{m}$. Abbreviations: pg, polar granule; sb, Stieda body; sr, sporocyst residuum.

mean length of its oocyst (17.4 vs. 16.5$)$ and mean dimensions of its sporocyst $(10.4 \times 5.7$ vs. $9.1 \times 4.7)$. However, it differs from $E$. knoxjonesi in oocyst shape (subspheroid vs. ellipsoid), mean width of oocyst (16.1 vs. 11.9), and L:W ratio of oocyst (mean 1.1, range $1.0-1.2$ vs. mean 1.4 , range 1.3-1.6). In addition, the oocyst wall of E. knoxjonesi appears thinner at one end, its sporocyst residuum is usually a small rosette of 3-4 granules, and its sporozoites contain 1-2 refractile bodies; in contrast, the oocyst wall of E. sevilletensis has no areas of thinning, its sporocyst residuum is a large, compact mass of many fine granules, and its sporozoites do not appear to contain refractile globules. Among Eimeria from other hosts in the Muridae, the new species most closely resembles Eimeria falciformis (Eimer, 1870) Schneider, 1875, from Mus

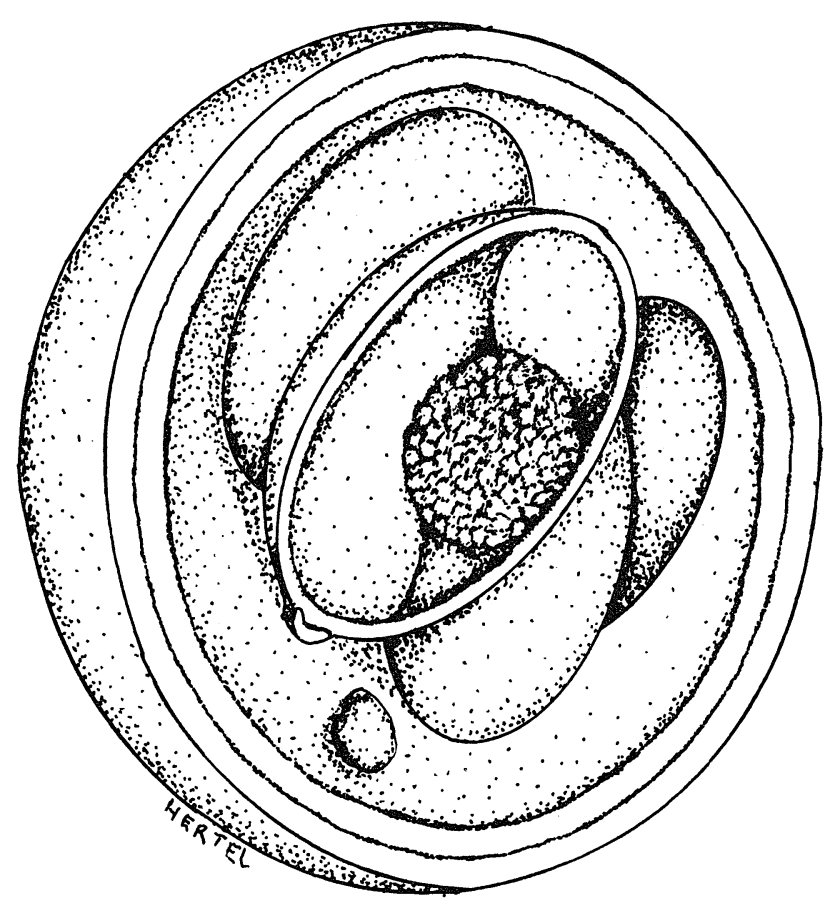

FIGURE 4. Composite line drawing of sporulated oocyst of Eimeria sevilletensis found in the feces of Onychomys species. Scale bar $=10$ $\mu \mathrm{m}$. musculus. The oocysts and sporocysts of both species overlap in shape and size (see Pellérdy, 1974; Levine and Ivens, 1990), their oocyst walls are smooth, and their Stieda bodies and sporocyst residua appear similar. However, the oocyst wall of the new species is obviously bilayered, whereas that of E. falciformis has been reported to have either 1 or 2 layers. In addition, E. sevilletensis consistently lacks an oocyst residuum, whereas the oocyst residuum of E. falciformis is variably present, the sporozoites of the proposed species lack refractile bodies, and those of E. falciformis contain a refractile globule at the broad end. Finally, an experimental inoculation of $\sim 1,000$ E. falciformis oocysts into an O. leucogaster (previously unexposed to any coccidia) did not result in a patent infection (data not shown).

Although the mean dimensions of the oocysts and sporocysts of $E$. sevilletensis collected from $O$. arenicola were statistically smaller than those isolated from $O$. leucogaster and $O$. torridus, and the mean dimensions of the oocysts collected from $O$. leucogaster were statistically smaller than those from $O$. torridus (Table I), oocysts and sporocysts from the 3 hosts overlapped in measurements and were identical in qualitative traits. In addition, oocysts isolated from $O$. torridus produced patent infections in experimentally infected $O$. leucogaster. For these reasons, we consider the 3 forms to represent a single species.

\section{DISCUSSION}

Members of the genus Onychomys can be found from southern Manitoba and eastern Washington state, through the southwestern United States, and into northern Mexico, and typically are found in desert scrub and shortgrass prairie habitats within these regions (Nowak, 1991). Nevertheless, at present, only 2 coccidia have been documented from these rodents, the first of which was described $40 \mathrm{yr}$ ago. The apparently low diversity of coccidia in these hosts may reflect the fact that few surveys for coccidia have included Onychomys spp.; this may be because they, like most predators, occur at relatively low densities (Nowak, 1991) and are thus less likely to be included in sizable numbers in surveys of the coccidia of rodents (McAllister et al., 1991).

In addition, the species we are describing may have escaped prior detection because, on cursory examination at lower magnifications, it may be confused with $E$. onychomysis. This was demonstrated when an experimental infection with a sample that had been misidentified as $E$. onychomysis yielded oocysts of the new species, a serendipitous result that prompted the infection experiments reported on above. This example is also noteworthy because the experimental infection was done in Jan- 
TABLE I. Comparison of Eimeria sevilletensis oocysts from 3 Onychomys host species for 4 quantitative characters (in $\mu$ m) with mean values followed by ranges in parentheses; sample sizes refer to the number of oocysts and sporocysts measured.*

\begin{tabular}{lccc}
\hline \multicolumn{1}{c}{ Character } & $\begin{array}{c}\text { O. arenicola } \\
(\mathrm{n}=43)\end{array}$ & $\begin{array}{c}\text { O. leucogaster } \\
(\mathrm{n}=37)\end{array}$ & $\begin{array}{c}\text { O. torridus } \\
(\mathrm{n}=25)\end{array}$ \\
\hline Oocyst length & $16.5(13.6-21.0)$ & $17.5(15.0-19.0)$ & $19.0(17.0-21.0)$ \\
Oocyst width & $15.3(12.8-19.0)$ & $16.2(13.5-18.0)$ & $17.0(15.0-19.0)$ \\
Sporocyst length & $9.9(9.0-12.0)$ & $\underline{10.5}(9.0-12.0)$ & $\underline{11.0}(10.0-12.0)$ \\
Sporocyst width & $5.5(4.5-7.5)$ & $\underline{5.7}(5.0-7.0)$ & $\underline{6.0}(5.0-7.0)$ \\
\hline
\end{tabular}

* Underscored character mean indicates no significant difference between those means (Fisher's LSD multiple comparisons test, $\alpha=0.05$ ).

uary 1997 , using $\sim 10-15$ oocysts that were isolated and stored in June 1993 , i.e., that were $\sim 3.5$ yr old, yet still viable. Pellérdy (1974) stated that, in general, the viability of oocysts stored at 4-6 C declines so that after 1-1.5 yr, the oocysts are useless for experiments. Nevertheless, our experience is that at least some of the Eimeria species of rodents may remain viable for 3-4 yr when stored in $2 \%(\mathrm{w} / \mathrm{v})$ aqueous potassium dichromate at $\sim 4 \mathrm{C}$.

\section{ACKNOWLEDGMENTS}

We thank the many students who, as members of our departmental Research Experience for Undergraduates Program, helped collect the host animals at the Sevilleta LTER and their parasites in the laboratory. We also thank M. Ernest for collecting fecal samples from hosts in Arizona, and L. Couch and L. Hertel who respectively photographed and drew oocysts for this paper. In addition, we are grateful to the United States Fish and Wildlife Service for allowing this research to take place at the Sevilleta National Wildlife Refuge. This project was supported by the UNM Sevilleta LTER program (NSF, BSR-8811906; DEB 95-9411976) and by a Survey and Inventory grant (NSF, DEB-95-05025) to D.W.D. and, in part, by a PEET grant (NSF, DEB-95-21687) to D.W.D. This is publication number 124 of the Sevilleta National Wildlife Refuge LTER project.

\section{LITERATURE CITED}

BANDONI, S. M., AND D. W. Duszynski. 1988. A plea for improved presentation of type material for coccidia. Journal of Parasitology 74: 519-523.

Brown, J. H., AND J. C. Munger. 1985. Experimental manipulation of a desert rodent community: Food addition and species removal. Ecology 66: 1545-1563.

Duszynski, D.W., G. EAstham, AND T. L. Yates. 1982. Eimeria from jumping mice (Zapus spp.): A new species and genetic and geographic features of $Z$. hudsonicus luteus. Journal of Parasitology 68: $1146-1148$.

- AND C. T. MCAllister. 1995. Coccidian parasites of Peromyscus attwateri and $P$. pectoralis in Texas with a description of a new species from $P$. pectoralis laceianus. Occasional Papers of the $\mathrm{Mu}-$ seum of Texas Tech University 156: 1-8.
- AND P. G. WILBER. 1997. A guideline for the preparation of species descriptions in the Eimeriidae. Journal of Parasitology 83: 333-336.

Frey, J. K., T. L. Yates, D. W. Duszynski, W. L. Gannon, And S. L. GARDNER. 1992. Designation and curatorial management of type host specimens (symbiotypes) for new parasite species. Journal of Parasitology 78: 930-932.

LEVINE, N. D., AND V. IVENS. 1990. The coccidian parasites of rodents. CRC Press, Inc., Boca Raton, Florida, 228 p.

,-- AND F. J. KRUIDENIER. 1957. New species of Eimeria from Arizona rodents. Journal of Protozoology 4: 80-88.

McAllister, C. T., S. J. Upton, J. V. Planz, and T. S. DeWalt. 1991. New host and locality records of coccidia (Apicomplexa, Eimeriidae) from rodents in the southwestern and western United States. Journal of Parasitology 77: 1016-1019.

NowAK, R. M. 1991. Walker's mammals of the world, 5th ed., Vol. 2. The Johns Hopkins University Press, Baltimore, Maryland, 1629 p.

Pellérdy, L. P. 1974. Coccidia and coccidiosis, 2nd ed. Akademiai Kiado, Budapest, Hungary, 959 p.

PFAFFENBERGER, G.S., AND D. DEBRUIN. 1986. Ectoparasitic overlap between sympatric Dipodomys ordii and Onychomys leucogaster (Rodentia) in eastern New Mexico, U.S.A. Journal of Medical Entomology 23: 201-207.

- K. KEMETHER, AND D. DeBruIN. 1985. Helminths of sympatric populations of kangaroo rats (Dipodomys ordii) and grasshopper mice (Onychomys leucogaster) from the high plains of eastern New Mexico. Journal of Parasitology 71: 592-595.

Stout, C. A., AND D. W. DuszYNSKI. 1983. Coccidia from kangaroo rats (Dipodomys spp.) in the western United States, Baja California and northern New Mexico with descriptions of Eimeria merriami sp. n. and Isospora sp. Journal of Parasitology 69: 209-214.

ThomAs, R. E. 1988. A review of flea collection records from Onychomys leucogaster with observations on the role of grasshopper mice in the epizootiology of wild rodent plague. Great Basin Naturalist 48: 83-95.

Upton, S. J., C. T. McAllister, D. B. Brillhart, D. W. Duszynski, AND C. D. WASH. 1992. Cross-transmission studies with Eimeria arizonensis-like oocysts (Apicomplexa) in New World rodents of the genera Baiomys, Neotoma, Onychomys, Peromyscus, and Reithrodontomys (Muridae). Journal of Parasitology 78: 406-413.

Wilson, W. D., J. A. HnidA, AND D. W. Duszynski. 1997. Parasites of mammals on the Sevilleta National Wildlife Refuge, Socorro, New Mexico: Cuterebra austeni and C. neomexicana (Diptera: Oestridae) from Neotoma and Peromyscus (Rodentia: Muridae), 19911994. Journal of Medical Entomology 34: 359-367. 